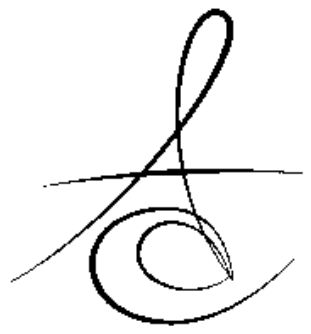

\title{
İZOLE ÇOKLU DİŞ EKSİKLİĞİ OLGUSUNA MULTİDİSİPLİNER YAKLAŞIM BİR YILLIK TAKİP
}

\section{ISOLATED LACK OF TEETH MULTIPLE APPROACHES MULTIDISIPLINARY the CASE ONE YEAR FOLLOW-UP}

\author{
Yrd. Doç. Dr. Mehmet Sertaç PEKER ${ }^{*}$ Doç. Dr. Şebnem Begüm TÜRKER ${ }^{* *}$ \\ Dr. Belen ÇAPAN* \\ Dr. Sibel BİREN ${ }^{* * *}$
}

Makale Kodu/Article code: 2078

Makale Gönderilme tarihi: 21.01.2015

Kabul Tarihi: 03.03.2015

\section{ÖZET}

Oligodonti, 3. büyük azı dişleri hariç, 6 veya daha fazla sayıda sürekli diş germ eksikliği olarak tanımlanan, ender görülen bir anomalidir. Oligodonti etiyolojik olarak herhangi bir klinik tabloya eşlik etmeden izole olarak görülebileceği gibi, çeşitli sendromlara veya ciddi sistemik bozukluklara bağlı olabilir. Oligodonti hastalarında fazla sayıda diş eksikliği nedeniyle psikolojik, gelişimsel, estetik ve fonksiyonel sorunlar görülür. Küçük yaştaki oligodonti hastalarının tedavisi genellikle pedodontist, ortodontist, cerrah ve protez uzmanından oluşan multidisipliner bir ekibin çalısması ile sağlanır.

$\mathrm{Bu}$ olgu bildiriminde izole oligodonti görülen 6 yaşındaki çocuk hastaya kaybolan estetik ve fonksiyonunun geri kazandırılması için yapılan multidisipliner tedavi sunulmuştur.

Anahtar Kelimeler: Oligodonti, overdenture, lazer

\section{ABSTRACT}

Oligodontia is a rare clinical condition, which defined as agenesis of six or more permanent teeth excluding the wisdom teeth. Oligodontia might be related to various systemic disorders nevertheless it can be isolated. Patients suffering from oligodontia may have psychological, developmental, esthetic and functional problems. Comprehensive rehabilitation of these patients include a fully integrated interdisciplinary team approach of pedodontist, orthodontist, oral and maxilla-facial surgeon, and prosthodontist. This case report presents a multidisciplinary treatment of a 6year-old child patient with non-syndromic oligodontia.

Key Words: Oligodontia, overdenture, laser

\section{GİRIŞ̧}

Diş agenezisi insanlarda en sık rastlanan dental anomalilerden biridir. Hipodonti, oligodonti veya anadonti şeklinde görülür. Oligodonti, 3. büyük azı dişleri hariç olmak üzere, 6 veya daha fazla sayıda sürekli diş germ eksikliği olarak tanımlanır ve prevalansı \% 0.16-0.84 arasındadır. Oligodonti ender görülen bir durumdur ve kızlarda erkeklere göre 3:2 oranında daha sık gözlenir. Etyolojisinde tek gen mutasyonu sık görülen bir etkendir. ${ }^{1,2}$

Oligodonti etiyolojik olarak herhangi bir klinik tabloya eşlik etmeden izole olarak görülebileceği gibi, çeşitli sendromlara veya ciddi sistemik bozukluklara bağlı olabilir. Bu sendromların başında Ektodermal Displazi, Down Sendromu, Dudak-Damak Yarıkları, Van Der Woude Sendromu, ve Reiger Sendromu bulunur. Oligodonti olgularında sıklıkla konik şekilli dişler, mikrodonti, daimi dişlerde sürme gecikmesi, alveol kret boyutlarında azalma, free-way boşluğunda artma, mine anomalileri ve süt dişlerinde retansiyon görülür. Oligodontinin sendromik ve sendromik olmayan formu, hastanın saç, tırnak, ter bezleri ve gözlerinin ayrıntılı fiziksel muayenesi ve konjenital bir bozukluğun olup olmadığının kontrolü ile ayırt edilebilir. $^{3,4}$ Dental anomalilerin tanısı için kullanılan en yaygın yöntem klinik muayene ile birlikte radyografik

*Marmara Üniversitesi Diş Hekimliği Fakültesi Pedodonti AD

** Marmara Üniversitesi Diş Hekimliği Fakültesi Protetik Diş Tedavisi AD

*** Marmara Üniversitesi Diş Hekimliği Fakültesi Ortodonti AD 
muayenedir. Diş eksikliğinin radyolojik tanısı için genellikle periapikal ve panoramik radyografiler kullanilır. $^{5}$

Oligodonti hastalarında, psikolojik, gelişimsel, estetik ve fonksiyonel sorunlar olabilir. Bu nedenle, bu hastalarda erken tanı ve tedavi çok önemlidir. Tedavi seçenekleri arasında, protetik yaklaşımın bu hastaların prognozunda en etkili yöntem olduğu kanıtlanmıştır. ${ }^{2,6}$

Bu olgu bildiriminde izole çoklu diş eksikliği görülen 6 yaşındaki çocuk hastaya kaybolan estetik ve fonksiyonunun geri kazandırılması için yapılan multidisipliner tedavi sunulmuştur.

\section{OLGU SUNUMU}

Altı yaşındaki erkek hasta, çoklu diş eksikliğine bağlı estetik ve çiğneme bozukluğu nedeniyle Marmara Üniversitesi Diş Hekimliği Fakültesi Pedodonti Kliniği'ne başvurdu. Alınan medikal anamnezinde hiç bir hastalık bulunmadı. Aile hikayesinde akraba evliliği yoktu ve başka hiçbir aile bireyinde diş eksikliği görülmedi. Hastada travma ya da çekim öyküsü yoktu ve daha önce yapılan genetik değerlendirmelerinde hiçbir sendrom saptanmadığı görüldü. Hasta, Frankı Davranış Değerlendirme Skalası'na göre "kesinlikle negatif" bulundu.

Ekstraoral muayenesinde fasiyal asimetri ve düz bir profil ile beraber yüz yüksekliğinde hafif bir azalma saptandı (Resim 1). 13.2 olarak hesaplanan Vücut Kitle İndeksi WHO'nun $2007^{7}$ değerlerine göre \%3 persentil aralığında olup bu sonuca göre hasta düşük kilolu olarak değerlendirildi. Yapılan intraoral ve radyografik incelemesi sonucunda $54,55,64,65,71$, $74,75,81,84,85,16,24,26,36$ ve 46 nolu dişlerinin mevcut olduğu; $11,12,13,14,15,17,21,22,23,25$, 27, 31, 32, 33, 34, 35, 37, 41, 42, 43, 44, 45, 47 nolu diş germlerinin ise olmadığı tespit edildi. Dişlerin boyut, şekil ve renklerinin normal olduğu gözlendi. Ayrıca hastada yüksek maksiller labial frenulum tespit edildi. Sefalometrik incelemede maksil- ler retrognati'ye bağlı Cl III iskeletsel maloklüzyon ve vertikal yönde düşük yüz yüksekliğine sahip olduğu görüldü (Resim 2,3,4,5).

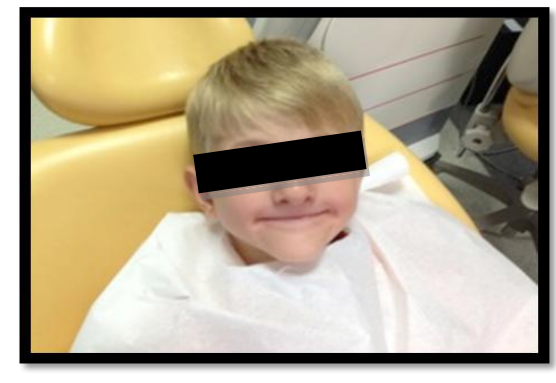

Resim 1. Hastanın cepheden görünümü

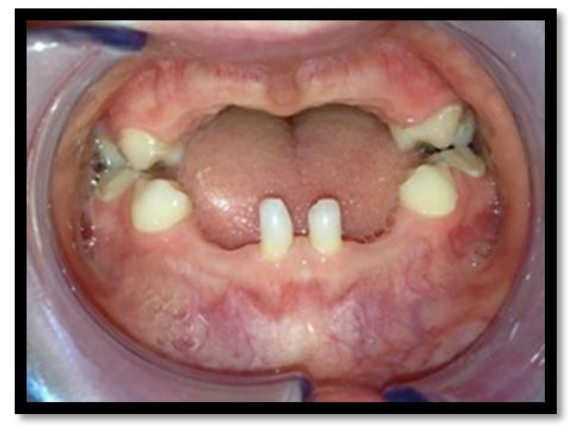

Resim 2. Ağız içi görünüm

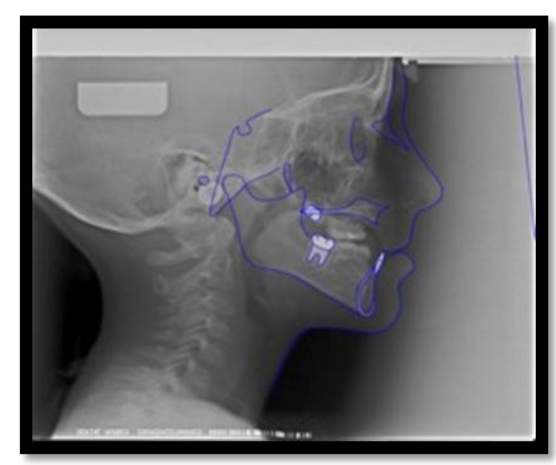

Resim 3. Hastanın başlangıç sefalometrik radyografisi

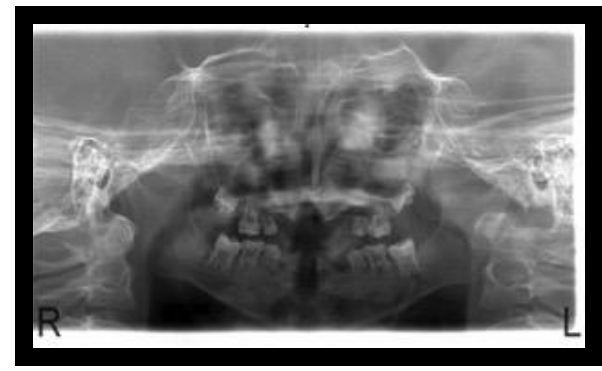

Resim 4. Hastanın panoramik radyografisi 


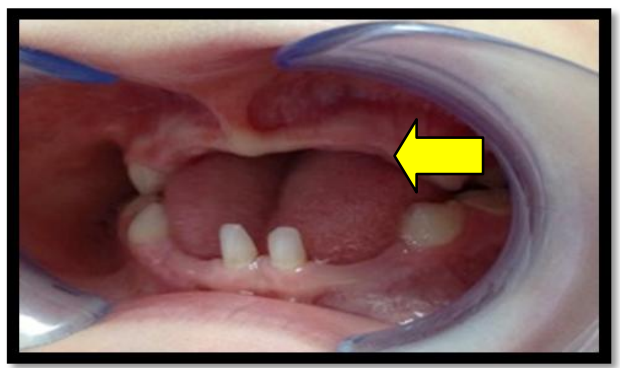

Resim 5. Labial frenulum

Eksik fonksiyon, fonasyon ve estetik rehabilitasyonu için dikey boyutun yükseltildiği overlay geçiş protezi yapılmasına karar verildi. Ancak 64 nolu dişin ileri çürük nedeniyle çekilmesi sonucu tutuculuk sağlamak amacıyla üst çeneye overdenture geçiş protezi yapılması planlandı. Alt çeneye ise hareketli dişli yer tutucu uygulandı. Hastanın maksiller yüksek frenulumuna diode lazer (810 nm; 2,5 W, Pulsed Mode, $400 \mu \mathrm{m}$ fiber uç, Gigaa Laser, Çin) ile frenektomi operasyonu yapıldı. İyileşmeyi takiben teşhis ölçüleri alınarak hastaya özel kaşık hazırlandı. Hasta, Frankl Davranış Değerlendirme Skalası'na göre "kesinlikle negatif" olduğu için dişler üzerinde herhangi bir preparasyon yapılmadan özel kaşıklar ile ikinci ölçü alındı. Modeller üzerinde kaide plağı ve mum duvar hazırlanarak dikey boyut belirlendi. Bir sonraki randevuda dişli prova yapıldı. Kapanış belirlendikten sonra protez bitirildi ve hastaya uygulandı (Resim $6,7,8,9,10,11,12,13)$.

Protezler takıldıktan sonra tekrar lateral sefalometrik radyografi çekildi. Başlangıç ve bitiş sefalometrik radyografileri karşılaştırıldığında,vertikal yön ilişkisini gösteren Gonion Menton /SN açısı başlangıçta $34^{\circ}$ iken vertikal boyutun yükseltilmesi sonucunda $40^{\circ}$ 'ye çıkarıldı. Diğer bir vertikal yön parametresi olan ANSMe/NMe oranı başlangıçta 52,9 olarak ölçülmüştür. Bu değer yüz yükseklik oranlarının düşük olduğunu göstermektedir. Tedavi sonucunda ANSMe/NMe oranı 55,9 ile ideale yaklaştırılmıştır. Tedavi başlangıcında sagital yön ilişkilerini gösteren SNA açıSı $74^{\circ}$, SNA açısı $75^{\circ}$ ve ANB açısı $-1^{\circ}$ bulunmuştur. Tedavi sonucunda SNA açıSı aynı kalırken, SNB açısı $73^{\circ}$ e düşmüş, ANB açısı ise $2^{\circ}$ olmuştur. Bu veriler ışı̆̆ında hastada vertikal boyut yetersizliğinde mandibula derin kapanışla birlikte anterior rotasyon yaptığı için Cl III ilişki göstermekteydi. Vertikal boyutun düzeltilmesiyle beraber sagital yön ilişkisi Cl I ilişkiye taşınmıştır. (Resim 14).

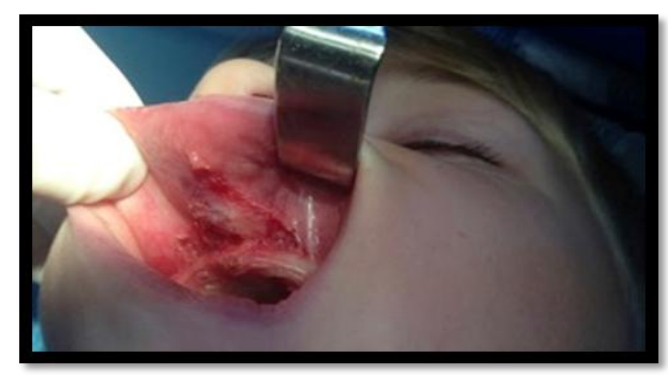

Resim 6. Diode lazer ile frenektomi

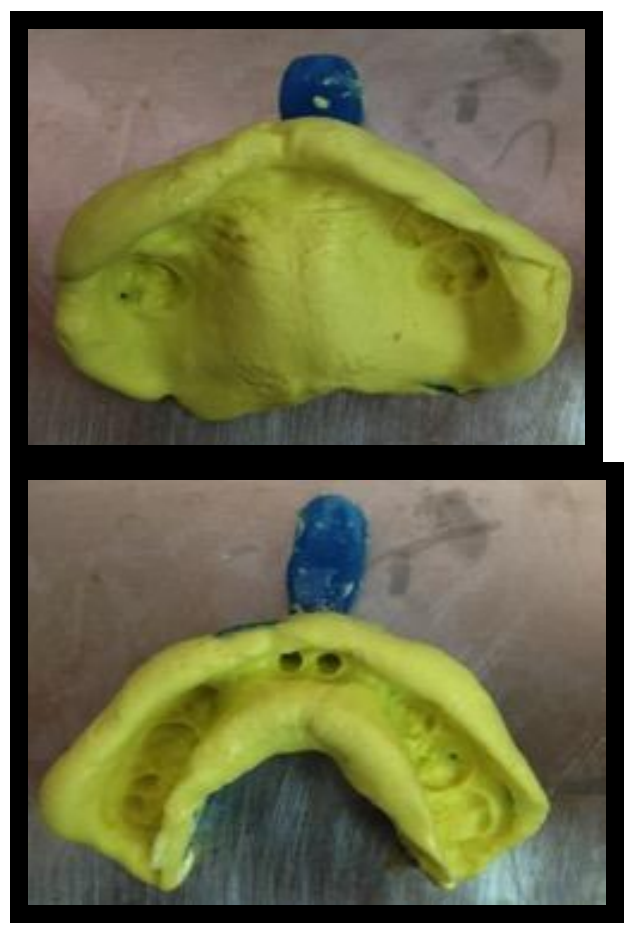

Resim 7. Hastaya özel kaşıklarla alınan ikinci ölçüler

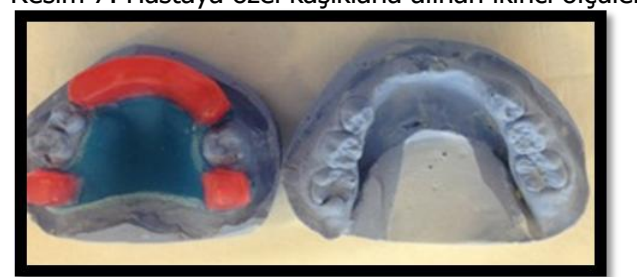

Resim 9. Üst çenede dikey boyutun belirlenmesi

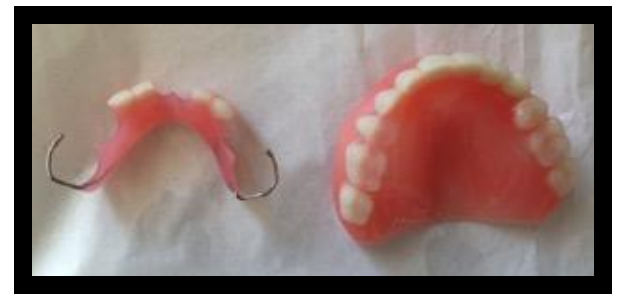

Resim 10. Protezlerin bitim görünümü 


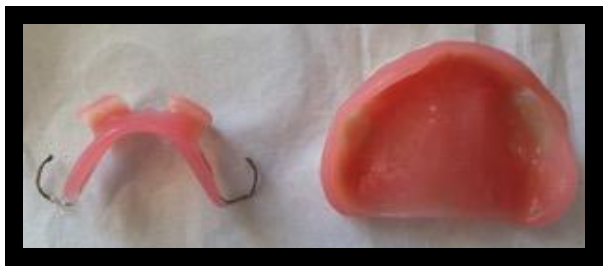

Resim 11. Protezlerin iç yüzeylerinin görünümü

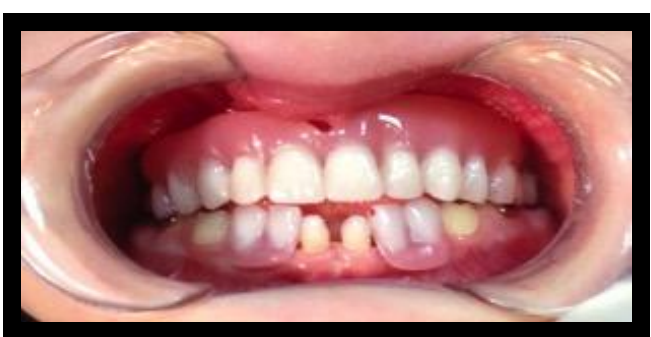

Resim 12. Protezlerin ağız içinde kapanışı

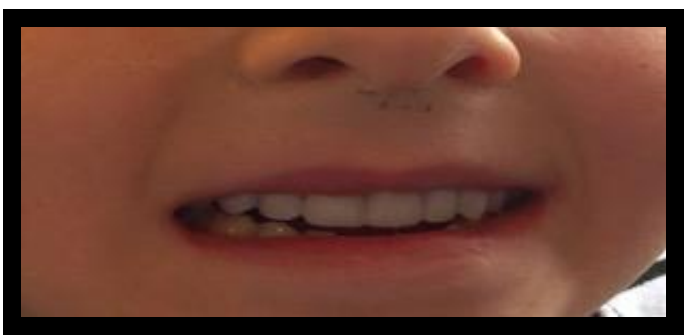

Resim 13. Hastanın ön cepheden görünümü

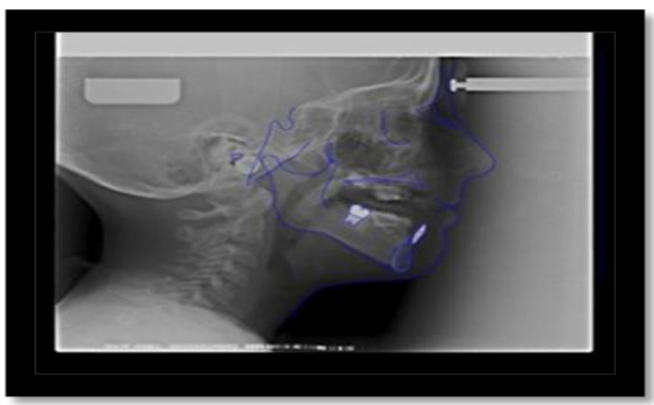

Resim 14. Hastanın protezler uygulandıktan sonra sefalometrik radyografisi

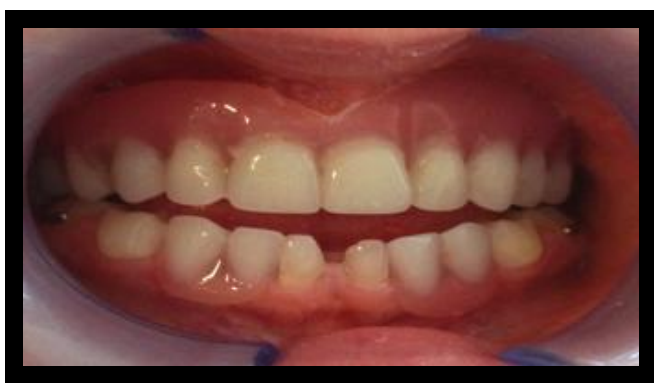

Resim 15.12 ay sonra protezlerin ağız içi kapanışı

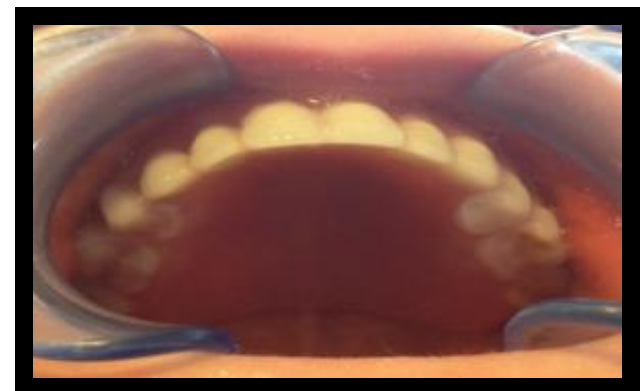

Resim 16.12 ay sonra üst protezin görünümü

Hasta 3 aylık kontrollere çağrıldı. Hastanın yapılan kontrollerinde protezlerden memnun olduğu, estetik, fonksiyon ve beslenme sorunlarının giderildiği, yüzün dikey boyut ilişkilerinde ve yumuşak doku profilinde olumlu değişiklikler olduğu gözlendi. 12. ay kontrolünde 16 ve 26 nolu dişlerin sürebilmesi için overdenture geçiş protezi içerisinde möllemeler yapıldı (Resim 14,15). 1. yıl sonunda, 13.5 olarak hesaplanan Vücut Kitle İndeksi WHO'nun $2007^{7}$ değerlerine göre $\% 5$ persentil aralığında bulundu. Bu sonuca göre protezlerin hastanın beslenmesini, büyüme ve gelişimini olumlu yönde etkilediği gözlendi. Daha iyi bir estetik görünüm ve fonksiyon sağlayan bu tedavi hem hasta hem de ebeveynleri tarafından olumlu karşılandı. Hastanın takibi ve tedavisi devam etmektedir.

\section{TARTIŞMA}

Oligodonti 3. büyük azı dişleri hariç altı veya daha fazla kalıcı dişin eksikliği olarak tanımlanır. Hipodonti ve oligodonti izole veya sendromik olmayan hipodonti / oligodonti ve sendromik hipodonti / oligodonti (ya da sendrom ile ilişkili hipodonti / oligodonti) olarak sınıflandırılır ${ }^{8}$. Oligodonti bir sendromun bir parçası ise genellikle deri, tırnaklar, göz, kulak veya iskelette değişiklikler vardır. Bu olgu sunumunda çocuk hastada dişlerde şekil anomalileri, deri ve göz değişiklikleri bulunmadığı ve daha önceki genetik değerlendirmeleri herhangi bir sendromla ilişkilendirilmediği için, hastamız izole oligodonti vakası olarak tanımlandı.

Oligodonti etiyolojisinde çeşitli faktörler rol almaktadır. Enfeksiyon (kızamıkçık, osteomiyelit), travma, ilaçlar (örneğin talidomid), genç yaşta alınan kemoterapi veya radyoterapi gibi çevresel faktörler etyolojiden sorumlu tutulmuştur. Diş eksikliğinde çevresel faktörler sorumlu olmasına rağmen, etiyolojide güçlü bir genetik bileşen olduğu da

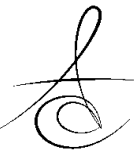


düşünülmektedir. Araştırmacılar hipodonti olgularından MSX1, PAX9 ve AXIN2 spesifik genlerinin sorumlu olduğunu bildirmişlerdir. ${ }^{3,4,6} \mathrm{Bu}$ genler diş gelişimi sırasında önemli bir rol oynayan transkripsiyon faktörlerini kodlar. Bazı izole oligodonti vakalarında EDA genindeki mutasyonlar da bildirilmiştir. ${ }^{8,9}$.

Üç yaşına kadar tüm süt dişleri ve 12-14 yaşlarına kadar, 3. büyük azı dişleri hariç, tüm daimi dişler ağızda yerini alır. Bu nedenle klinik muayenede 3-4 yaşlarındaki bir çocuk süt dişlerinin teşhisi için uygundur, aynı şekilde 12-14 yaşlarındaki bir çocukta da konjenital eksik daimi dişler teşhis edilebilir. Hipodonti tanısını koymak için, klinik muayene ile birlikte panaromik radyografi kullanımı önerilmektedir. ${ }^{8}$

Venkataraghavan ve ark. ${ }^{10} 18$ süt dişinin eksik olduğu ve daimi diş germlerinde dentinin kusurlu görüldüğü vakalarını bildirmişlerdir. Shilpa ve ark. ${ }^{11}$ ve Oshima ve ark. ${ }^{12}$ daimi diş germlerinin röntgende görüldüğü ancak süt dentisyonda eksik dişlerin bulunduğu izole oligodonti vakalarını bildirmişlerdir. ${ }^{13}$ Bizim vakamızda ise 10 süt dişi ve 22 daimi diş germi eksiliği görülmektedir.

Oligodonti hastalarında, psikolojik, estetik ve fonksiyonel problemler görülür. Bu nedenle oligodonti hastalarının erken tanı ve tedavisi çok önemlidir. Oligodonti vakaları uygun bir tedavi planlaması ile düzenli kontrol altında olmalıdır. Diş eksikliğinin yaygınlığı ve hastanın yaşı uygun tedavinin seçimi ve planlanmasında önemli bir rol oynamaktadır. Mevcut dişlerin durumu ve sayısı, eksik diş sayısı, çürük dişlerin varlığı, destek dokuların durumu, oklüzyon ve inter-okluzal istirahat boşluğu (rest space) ayrıca değerlendirilmelidir. Bu hastaların tedavisi pedodontist, ortodontist, ağız, diş, çene cerrahı ve protez uzmanının bulunduğu multidisipliner bir ekip yaklaşımı ile sağlanmalıdır. ${ }^{3,4,13}$ Hastamızın tedavisi de pedodontist, ortodontist ve protez uzmanından oluşan bir ekip ile planlanmıştır.

Maksiller frenum müköz membran, bağ dokusu ve bazen de kas liflerinden oluşan anotomik bir yapıdır. Yüksek bağlanması genellikle frenulumun hipertrofisiyle ilgilidir. Anormal frenum frenektomi işlemi ile tedavi edilebilir. Konvansiyonel cerrahi tekniklere göre lazer kullanımının lokal anestezi gerektirmemesi, kansız bir operasyon sahası sağlaması, işlem sonunda dikiş atılmaması ve periodontal pat ile örtülmeye gerek kalmaması, hızlı olması, daha az skar dokusu ile iyileşmesi gibi avantajları mevcuttur. ${ }^{14}$ Yapılacak olan protezin stabilizasyonu ve hastanın tedavisinde sağlamış olduğu yukarıdaki avantajları gözönüne alınarak frenektomi işlemi için $810 \mathrm{~nm}$ diyot lazer kullandık.

Dişsizlik; konuşma bozukluğu, deforme edici dil alışkanlıkları ve çiğnemenin zor veya imkansız olması nedeniyle kötü beslenmeye neden olur. Alveoler kemiğin gelişimi diş varlığına bağlı olduğundan, oligodonti veya anodontili çocuklarda alveoler kemik atrofisi görülür. Bu nedenle protezi desteklemek için çok az kemik sırtı (ridge) bulunur. Yine de protetik tedavinin, bu hastaların tedavisinde en etkili yol olduğu bildirilmiştir. ${ }^{6,15,16}$

Khazaie ve ark. ${ }^{17}$ küçük çocukların protez kullanımına adapte olabilmeleri için protetik tedavinin okul öncesi yıla kadar yapılması gerektiğini vurgulamışlardır. Derbanne ve ark. ${ }^{18} 40$ 'tan fazla anodonti ve oligodonti hastasını hareketli protez ile tedavi ettikten sonra, protez rehabilitasyonu ne kadar erken yaşta başlarsa, fonksiyon, sosyal integrasyon ve hastaların kendine güvenlerinin o kadar iyi gelişeceğini belirtmişlerdir. Erken müdahale çocuğa konuşma, çiğneme ve yutma fonksiyonlarının normal olması, uygun yüz desteği oluşumu ve temporomandibular eklem fonksiyonu gelişimi fırsatı tanımaktadır. Protetik tedavi çiğneme kaslarının tonusunu artırır ve normal çiğneme, yutma ve düzenli fonasyon sağlar. ${ }^{16}$ Altı yaşında olan hastamızda protez uygulanması sonrasında çocuğun okul ve aile içerisindeki davranışlarındaki olumlu değişim, konuşma ve beslenme alışkanlarının düzelmesi ile bu kriterlere uygun olduğunu düşünmekteyiz.

Oligodonti hastalarına yapılacak protetik tedaviler arasında implant, hareketli protez, sabit protez, ve adeziv teknikler bulunur. Hareketli parsiyel protezler (HPP), overlay ve overdenture protezler nispeten basit ve hızlı yöntemler olup ağız ve çene cerrahisinin mümkün olmadığı vakalarda kullanılır. Tam protezler kabul edilebilir estetik ve fonksiyonel sonuçlar sağlamasına rağmen, oligodonti hastalarındaki dişsiz alveoler sırtlar yeteri kadar gelişmediği için protezin retansiyon ve stabilitesi tehlikeye düşebilmektedir. Oligodonti hastaları erken yaşlardan itibaren protezin desteklenmesi için alveolar kretlere bağımlı olduklarından, oligodontili bireylerde alveolar kemiğin korunması zorunludur. Alveolar kretleri örten ve kısmen doğal dişler, kökler, ya da implant tarafından desteklenen overdenture protezler, oligodonti hastalarının tedavisinde tatmin edici bir yöntemdir.2,6,15,16 Sunulan 
vakada hastanın dikey yön anomalisini düzeltmek, eksik fonksiyon, fonasyon ve estetiğini rehabilite etmek amacıyla bir overdenture geçiş protezi hazırlandı. Franklin Davranış Değerlendirme Skalası'na göre hasta "kesinlikle olumsuz" bulunduğundan, dişlerde herhangi bir preparasyon gerçekleştirilmedi.

Doğal diş ya da implantlar ile desteklenen overdenture protezler oligodonti hastalarının tedavisinde kullanılmaktadır. Bu protezlerin pahalı olmamaları, kısa sürede tamamlanabilmeleri ve modifiye edilebilmeleri gibi avantajları vardır. ${ }^{9,19}$ Overdenture protezler ideal bir oklüzyon sağlar, dikey boyutu arttırır ve yüz estetiğinin önemli ölçüde iyileştirilmesini sağlar. Böylece hastaların dış görünüm problemleri önemli ölçüde azalır. Öte yandan, overdenture protezler hem dişleri hem de dişeti kenarlarını örtmektedir. Bu durum destek dişleri, remineralizasyonu sağlayan normal tükürük temasından izole edeceğinden; çürük oluşumu, gingivit ve periodontal yıkım oranı artabilmektedir. Çürük riskini azaltmak için florürlü diş macunlarının overdenture protezin iç yüzeyine günlük olarak uygulanmaları önerilmektedir. Hijyen kontrolü ve büyüme-gelişimin takibi için periyodik kontroller yapılmalıdır. ${ }^{9,13}$

Tedavinin takibi çok önemlidir. Dental profilaksi, muayene, oral hijyen eğitimi ve protez düzeltmeleri için 3-6 ayda bir düzenli konroller gereklidir. Oligodontili çocuk hastayı tedavi etmek için büyüme ve gelişme hakkında tam bir bilgiye sahip olmak gerekir ve protezin modifikasyonu ve / veya değiştirilmesi için uzun süreli takip gereklidir. Protez ve oklüzyonun düzenlenmesi amacıyla çene büyümesi düzenli aralıklarla periyodik olarak görüntülenmelidir. Protezler dişlerin düşmesi sonucu akrilik eklenmesiyle veya diş sürmesi için, protezin içinden aşındırılması ile modifiye edilebilir. Büyüme ve gelişme döneminde olan çocuklarda protezin yenilenmesi gerekmektedir. Büyüme stabilize olduğunda, osseointegre implantlar proteze destek, stabilizasyon ve tutuculuk sağlamak için alternatif bir yöntem olabilir. ${ }^{16,20,21}$ Hastamız bir yıldır takip altındadır. Hastanın proteze uyumu mükemmel bulunmuştur. Bu uygulamanın çocuk hastanın psikolojisine olumlu katkısı olduğu, özgüveninin geliştiği, daha önce konuşmaya çekinen çocuğun rahatlıkla konuşmak istediği gözlenmiştir.

\section{SONUÇ}

Oligodonti vakaları klinisyenler tarafından dikkatlice değerlendirilmelidir. Erken tanı ve tedavi bu hastalarda oldukça önemlidir. Çocuk hastalarda oral fonksiyonların devamlıığını sağlamak, normal gelişimi desteklemek ve çocukların kendine güvenlerini geliştirerek sosyal becerilerini arttırmak için protetik tedavi olabildiğince erken yaşta yapılmalıdır.

Çoklu diş eksikliği olgularında overdenture protezler alternatif bir tedavi yaklaşımı olarak kabul edilebilir. Bu olgu sunumunda da overdenture protez ile kaybolan estetik ve fonksiyon düzenlenmiştir. Ancak overdenture protez kullanan hastalar çürük oluşumu açısından yüksek risk altındadırlar. Bu nedenle bu hastalara ağız hijyen eğitimi verilmeli, protezlerini düzenli olarak temizlemelerinin önemi anlatılmalı ve sık kontroller yapılmalıdır. Erken yaşta hastalara uygulanan protezler, sürecin devamı için klinisyen, hasta ve veliler arasında iyi bir iletişim olmasını gerektirmektedir.

\section{KAYNAKLAR}

1. Ruf S, Klimas D, Hönemann M, Jabir S. Genetic background of nonsyndromic oligodontia: a systematic review and meta-analysis. J Orofac Orthop. 2013 Jul;74:295-308.

2. Heuberer S, Dvorak G, Zauza K, Watzek G. The use of onplants and implants in children with severe oligodontia: a retrospective evaluation. Clin Oral Implants Res. Jul 2012;23:827-31.

3. Tangade $\mathrm{P}$, Batra M. Non Syndromic Oligodontia: Case Report. Ethiop J Health Sci. July 2012; 22: 219-21

4. Bural C, Oztas E, Ozturk S, Bayraktar G. Multidisciplinary treatment of non-syndromic oligodontia. Eur J Dent; Apr 2012;6:218-26.

5. Correia MF, Nogueira MN, Bedran TB, Palomari Spolidorio DM. Aesthetic rehabilitation of oligodontia in primary dentition with adhesive partial denture. Case Rep Dent. 2013; 2013: 872476.

6. He X, Shu W, Kang Y, Li Z, Zhang J, Kari K, Meurman $\mathrm{JH}$. Esthetic and functional rehabilitation of a patient with nonsyndromic oligodontia: a case report from China. J Esthet Restor Dent. 2007; 19:137-42.

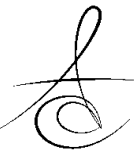


7. Pekcan G. Beslenme Durumunun Saptanması. 1. Basım. Klasmat Matbaacılık, Ankara; 2008, s:49.

8. Vanishree G, Surekha A, Vikram Simha R. Oligodontia Of Permanent Teeth- Rare Case Reports. Annals and Essence of Dentistry. Oct Dec. 2010; 2:101-4.

9. Thalji G.N., Cooper L.F. The Role of Complete Overdentures in Esthetic Rehabilitation of the Adolescent Oligodontia Patient. A Case Report. Wiley Periodicals, Complete Overdentures. 2010; 22: 213-21.

10. Venkataraghavan K, Anantharaj A, Prasanna P, Sudhir R. Oligodontia in the primary dentition: report of a case. J Dent Child (Chic). 2007; 74:154-6.

11. Shilpa, Thomas AM, Joshi JL. Idiopathic oligodontia in primary dentition: case report and review of literature. J Clin Pediatr Dent. 2007; 32:65-7.

12. Ooshima T, Sugiyama K, Sobue S. Oligodontia in the primary dentition with permanent successors: report of case. ASDC J Dent Child. 1988; 55:75-7.

13. Moses J, Gurunathan D, Rangeeth BN, Kannan KS. Non-syndromic oligodontia of primary and permanent dentition: 5 year follow up- a rare case report. J Clin Diagn Res. Apr 2013;7:776-9.

14. Gontijo I, Navarro RS, Haypek P, Ciamponi AL, Haddad AE. The applications of diode and Er:YAG lasers in labial frenectomy in infant patients. JDent Child (Chic) 2005; 72 1:10-5.

15. Pigno M.A., Blackman R.B., Cronin R.J., Cavazos E. Prosthodontic management of ectodermal dysplasia: A review of the literature. J Prosth Dent. November 1996; 76: 541-5.

16. Teixeira Marques NC, Gurgel CV, Fernandes AP, Lima MC, Machado MA, Soares S, Oliveira TM. Prosthetic rehabilitation in children: an alternative clinical technique. Case Rep Dent. 2013; 2013: 512951.

17. Khazaie R, Berroeta EM, Borrero C, Torbati A, Chee $W$. Five-year follow-up treatment of an ectodermal dysplasia patient with maxillary anterior composites and mandibular denture: a clinical report. J Prosth. 2010; 19: 294-8.

18. Derbanne M A, . Sitbon MC, Landru M M, Naveau A. Case report: early prosthetic treatment in children with ectodermal dysplasia. E Arch Paediatr Dent. 2010; 11: 301-5.
19. Türker B., Kazazoğlu E., Artın T. Hipodontili Bir Olguda Protetik Tedavi Yaklaşımı. İÜ Diş Hek Fak Der. 1997; 31: 176-83.

20. Schneidman E, Wilson S., Spuller R.L.Complete overlay dentures for the pediatric patient: case reports. Pediatr Dent. September 1988; 10: 222-5.

21. Dali M, Singh R, Naulakha D. Idiopathic nonsyndromic tooth agenesis: $A$ report of rare three. J Interdisc Dent. Sep-Dec 2012; 2: 190-4.

\section{Yazışma Adresi}

Yrd. Doç. Dr. M. Sertaç PEKER

Marmara Üniversitesi

Diş Hekimliği Fakültesi

34365 Nişantaşı

İstanbul,Türkiye

Tel: 02122483127

e-mail: sertacpeker@hotmail.com 